\title{
Variable Speed DC Generator Voltage Control using a Multistage Comparator
}

\author{
$1^{\text {st }}$ Augustinus Sujono \\ Dept. Electrical Engineering \\ Universitas Sebelas Maret \\ Surakarta, Indonesia \\ agus.sjn.te16@gmail.com \\ $4^{\text {th }}$ Joko Slamet Saputro \\ Dept. Electrical Engineering \\ Universitas Sebelas Maret \\ Surakarta, Indonesia \\ jssaputro89@staff.uns.ac.id
}

\author{
$2^{\text {nd }}$ Feri Ardriyanto \\ Dept. Electrical Engineering \\ Universitas Sebelas Maret \\ Surakarta, Indonesia \\ feri.adriyanto@staff.uns.ac.id \\ $5^{\text {th }}$ Agus Ramelan \\ Dept. Electrical Engineering \\ Universitas Sebelas Maret \\ Surakarta, Indonesia \\ agusramelan@staff.uns.ac.id
}

\author{
$3^{\text {rd }}$ Hari Maghfiroh \\ Dept. Electrical Engineering \\ Universitas Sebelas Maret \\ Surakarta, Indonesia \\ hari.maghfiroh@gmail.com
}

\begin{abstract}
DC generator with variable rotation will produce uncontrolled voltage, causing problems in its utilization. In this study, it is proposed to develop a voltage control on the generator, in order to produce a fairly controllable and reliable voltage, with an analog circuit using a multistage comparator. Control of the generator output voltage is carried out by adjusting the field current from a separate voltage source which is forwarded to the resistance which is regulated based on the generator output voltage level with a multilevel comparison system. The results obtained are the output voltage ranges from 26 to 30 Volts and the output current ranges from 3 to 20 Amperes. This provides operational safety for the generator and battery. This technology can be used in dc generator systems in automotive engines, windmills, and other power plants.
\end{abstract}

Keywords—speed control, generator, multistage, comparator

\section{INTRODUCTION}

Generators in automotive engines that operate at various revolutions, as well as electric power generation sourced from renewable energy, such as wind energy, ocean waves or tidal energy, will provide uncontrolled output voltage from the generator which will cause problems for users. So it is necessary to develop a voltage control system that is able to overcome these problems.

For this reason, the generator used is a dc generator, with its own excitation which comes from the battery. Apart from providing power to the load, the DC generator also charges the battery, as shown in Fig. 1.

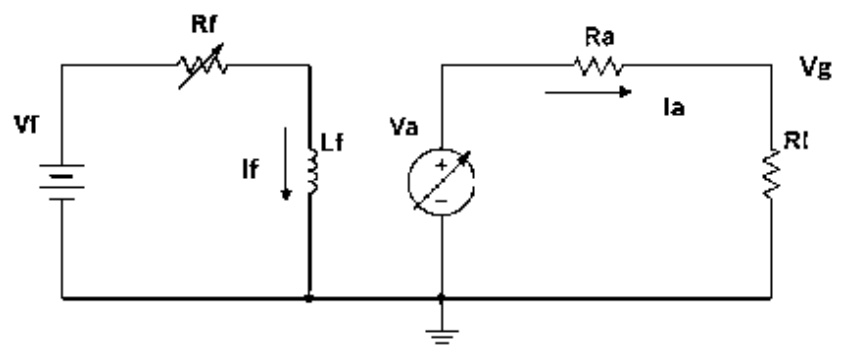

Fig. 1. DC generator separate excitation

The output voltage of the generator depends on the field flux and its rotation, while the field flux depends on the field current, as in the following equation [1] :

$$
\begin{aligned}
& V_{a}=K_{a} \cdot \emptyset \cdot \omega \\
& \emptyset=K_{f} \cdot I_{f}
\end{aligned}
$$

$$
\begin{aligned}
I_{f} & =\frac{V_{f}}{R_{f}} \\
V_{g} & =V_{a}-I_{a} R_{a}
\end{aligned}
$$

In equation (1) the generator output voltage $(\mathrm{Vg})$ depends on the rotation speed $(\omega)$ and in equation (2) the field flux $(\Phi)$ generated by the field current (If). While the field current can be controlled by changes in field resistance (3). In other words: the generator output voltage can be controlled by adjusting the field resistance in accordance with the generator rotation speed.

In addition to the flux and rotation of the generator, varying loads also affect the output voltage of the generator, so an AVR (Automatic Voltage Regulator) is needed, as explained by P. G. Dhawale et.all [2], that: AVR plays a key role in generating stations. To maintain voltage stability of the generator the terminal voltage should remain constant all the times. In a large interconnected system manual regulation is much complicated and therefore automatic generation and voltage regulation is necessary.

The Automatic Voltage Regulator (AVR) is widely used in industrial application to obtain the stability and good of different electrical apparatus, proposed by Matthew E. Oboh et.all [3], proposed to get output of the alternator, the field excitation is controlled by the AVR. The AVR maintains the constant voltage up to certain of the load current which is independent of the generator speed and load. The excitation control for the generator is designed by using silicon controlled rectifier (SCR) in order to improve the overall effectiveness of the synchronous generator.

Besides the generator output voltage that needs to be adjusted automatically, the frequency also needs to be considered as explained by: Siraparapu Satyanarayana et.all. [4] were proposed to show the interaction between the LFC (load frequency control) and the AVR loops in the Power Plant. The combinational effects of these two LFC and AVR loops were studied by extending the linear zed AGC (automatic generation control) system. A complete system model for LFC with Speed Governor. Turbine, Integral controller and Power System and AVR with Excitation System and PID controllers were described.

Further arrangement using the Direct Control System and Cascade Control System proposed by: D. S. Mota et.all [5] which describes: compares the behavior of two different control structures of automatic voltage regulators of synchronous machines equipped with static excitation systems. The systems are: "Direct Control", has a single 
proportional-integral (PI) regulator and "Cascade Control", was inspired on control loops of commercial DC motor drives. Such drives employ two PIs in a cascade arrangement, the external PI deals with the motor speed while the internal one regulates the armature current.

To increase reliability, it is necessary to use the Robust Control of Terminal Voltage, proposed by: Fariya Tabassum et.all [6] which explains that: an automatic voltage regulator (AVR) system controlled by an optimal linear-quadraticGaussian (LQG) controller augmented with An integral action, for maintaining constant output voltage. This controller is to keep stable terminal voltage of a power system during sudden load variation.

The speed and magnitude of ocean wave energy that is always changing, requires specific voltage control as described by M. Alberdi et.all [7]: One of the main problems that arise when dealing with Oscillating Column-based wave power plants equipped with Doubly-Fed Induction Generators, is the need for adequate Fault-Ride-Through during voltage drops. An innovative Fault-Ride-Through solution is proposed consisting of a control scheme that matches the control of airflow, an active crowbar and a variable frequency converter, which complies with the Code Grid. It has also implemented controls that adjust the controller reference according to pressure drop and voltage reduction, increasing active and reactive power control capability and Fault-Ride-Through capability during voltage drop.

In wind turbine power plants, in order to control the generator voltage it is necessary to add a pitch setting as described by: Phuong T.H. Nguyen et.all [8] that: proposes a control strategy for a wind energy conversion system (WECS) based on permanent magnet synchronous generator (PMSG) to improve low-voltage drive through (LVRT) capability. The nonlinear relationship between generator speed and DC-link voltage is considered using feedback linearization. To support networking during LVRT, the DClink voltage is controlled by the engine side converter (MSC). The kinetic energy stored in the inertia of the wind turbine is used to compensate for the lower voltage. Furthermore, pitch angle control is used to ensure stable operation, and to ensure that the rotor speed does not exceed the rated value.

In automotive systems, it is proposed to use a Digital control of a bidirectional DC / DC converter by: Wojciech Wojtkowski et.all [9], who explained that: By implementing an FPGA based solution, nine waveforms are required, control of the MOSFET switch ( 9 control channels) is obtained as well as the desired control frequency range. The solutions presented can be used in vehicles with hybrid or purely electric drive, where a low-voltage source (battery pack or super capacitor) works together with a high-voltage device (electric motor, generator, high-voltage battery stack).

Furthermore, for the use of Hybrid Electric Vehicles, it is proposed by Sabin et.all [10], to take advantage of the MultiLevel Predictive Cascade DC-Link Voltage Control, with the explanation that: for this challenge using a multi-rate predictive cascade chamber control structure with a focus on the design of the outer loop voltage controller. First, the mathematical model, including the dynamics of the inner current control loop, is obtained and linearized. Second, a one-step predictive controller model based on the flexible control of the Lyapunov function is used to control the DClink voltage.

The AVR performance improvement was carried out by: Emre Çelika at.all [11], by modifying the symbiotic organisms search (SOS) algorithm, which states that: tried to solve the problem of the efficient design of a proportional + integral + derivative (PID) controller applied to the popular automatic voltage regulator (AVR) system using the recently introduced SOS algorithm. The PID controller design requires precise determination of three control parameters. Such a design problem can be taken as an optimization task and SOS called to know better controller parameters through a new cost function, which makes it possible to evaluate the behavior of controls in the time domain and frequency domain. For performance analysis, different analytical techniques are used such as transient response analysis, root locus analysis, and code analysis. In addition, a robustness analysis of the closed-loop control system set by SOS is carried out with due regard to parameter uncertainty and external disturbances.

The problem of power generation becomes more complex when the prime mover rotation is not constant, causing more uncertainty in output, as is the case with wind power systems. Here the wind, which is always changing speed and direction, demands a generator control system to deal with more complicated problems. In this effort, efforts have been made by Du Bo at.all [12], through the power / reactive voltage characteristics of today's mainstream wind generators, large-scale wind farms and cluster wind farms. It is to carry out a detailed analysis of a single wind farm's tension control and propose an automatic and coordinated tension control action with an assessment of the voltage / reactive power sensitivity matrix representing the stability of the power system.

With the consideration of these various references, in this study, the problem faced is the design and implementation of the AVR from the DC generator in the vehicle, which has varying loads and revolutions, so the problem will be more complex. Here is a battery available to provide backup power and use the entire system, including the need for field currents in the excitation system. In addition, the battery will provide additional control of the generator voltage and the battery will be charged by the generator when its contents are reduced. Thus the output voltage does not need to be stable at a certain voltage level, but sufficient in the maximum and minimum voltage range.

In order to simplify the AVR system, the generator voltage control will be carried out using the overall field current control with the current source from the battery which has a constant voltage. Taking into account existing references and the need for control of the generator output voltage, which ranges from the maximum and minimum voltages, a field current control system is designed in a multistage excitation system, based on the magnitude of the generator output voltage.

\section{Multistage ExCitation System}

\section{A. Multistage Comparator Excitation System (MCES)}

The multistage excitation system will be used to adjust the level of the generator output voltage by using a field multistage resistor which is adjusted to the level of the 
generator output voltage. To detect the generator output voltage, a multistage comparator is used to determine the voltage in stages.

The multistage comparator is used to detect the output voltage level of the generator. This will then be used to activate a multistage resistor which will control the field current in the excitation system. So by controlling the multistage resistance excitation will control the field current level, so that the generator output voltage level is also controlled. The block diagram is given in Fig. 2.

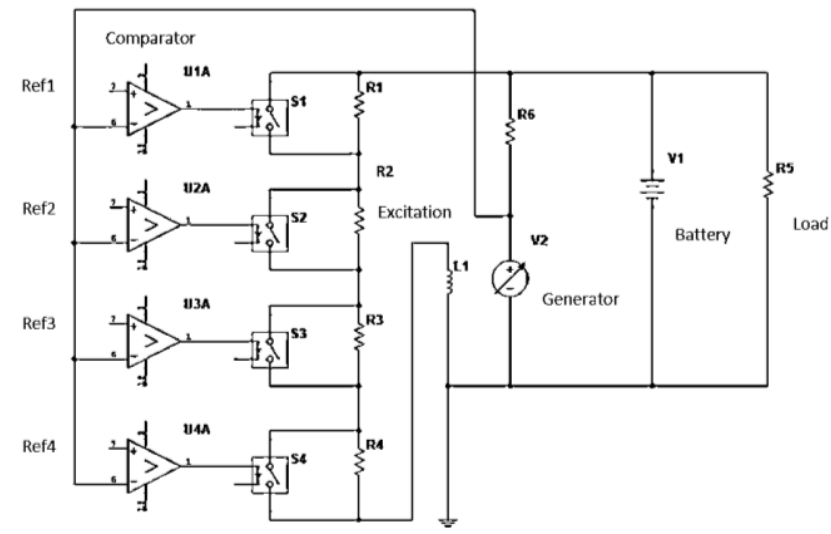

Fig. 2. Multistage comparator excitation system (MCES)

Fig. 2. shows a diagram of the multistage comparator excitation system (MCES), which regulates the excitation field current in order to control the generator output voltage in stages. The comparator will detect the generator output voltage, to determine the appropriate resistor size required. If the generator voltage is too low or not high enough, which means the excitation resistor is too large so that the resistor needs to be reduced, the comparator will reduce the unnecessary resistor through the relay. Conversely, if the generator voltage is too high or needs to be reduced, which means the excitation resistor is too small so that the resistor needs to be added, the comparator will open or close the required resistor through the relay.

\section{B. Generator Characteristic}

On the DC generator, experiments were carried out in order to determine its characteristics, to determine the required parameter values for MCES. Experiments are carried out by giving a certain rotation with a large variation of a certain excitation voltage and current and the resulting generator voltage is recorded. Likewise, at various other rotations, the amount of excitation voltage and current and the resulting generator voltage is recorded. The experimental results are depicted in Fig. 3. .

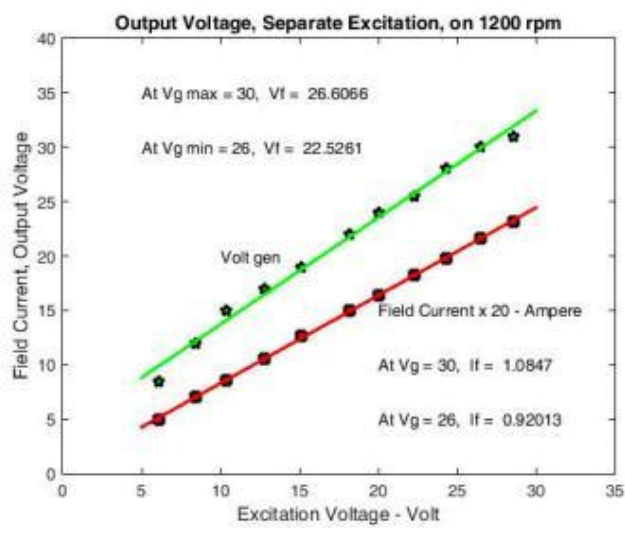

(a)

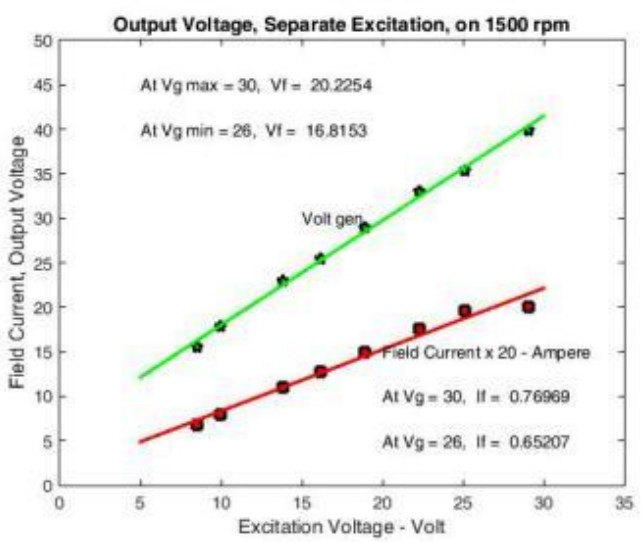

(b)

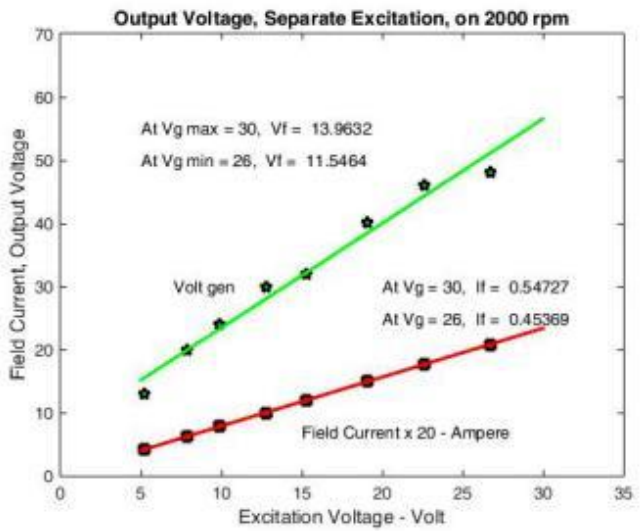

(c)

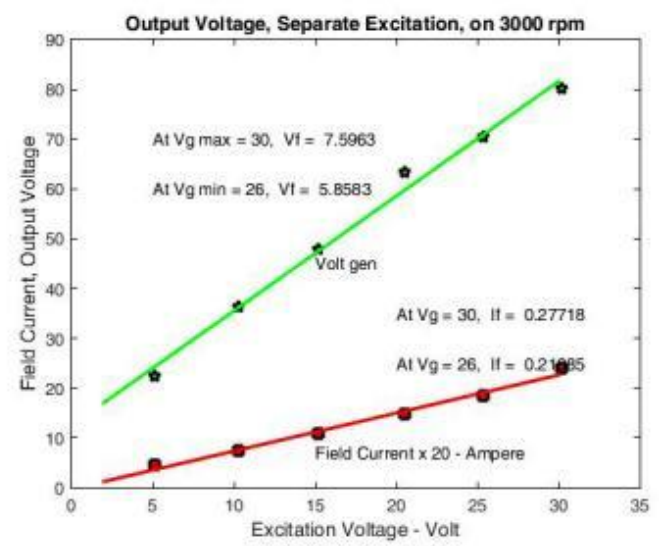

(d)

Fig. 3. Generator characteristic 
Fig. 3. shows the characteristics of the generator that will be given AVR, based on the rotation speed : a). $1200 \mathrm{rpm}$, b). $1500 \mathrm{rpm}, \mathrm{c}) .2000 \mathrm{rpm}$ and d).3000 rpm. The figure shows the excitation current level and the resulting generator voltage, at a certain excitation voltage and rotation.

\section{AVR Vevelopment}

Based on the characteristics of the generator and the multistage comparator exciter system, the excitation current requirements can be arranged to produce an output voltage of a maximum of 30 Volts and a minimum of 26 Volts, at a certain rotation rate. The results are given in Fig. 4 .

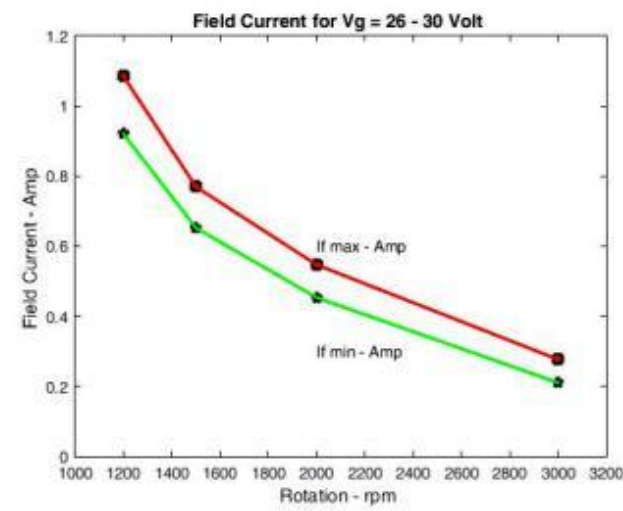

Fig. 4. Field current for generator voltage output $26-30$ Volt

Fig. 4. shows the amount of field current required to produce a generator output voltage ranging from 26 to 30 volts, at a certain rotation rate. If the source of the excitation current comes from a 24 Volt battery, then the level of resistance required to adjust the excitation current can be calculated and the results are given in Fig. 5.

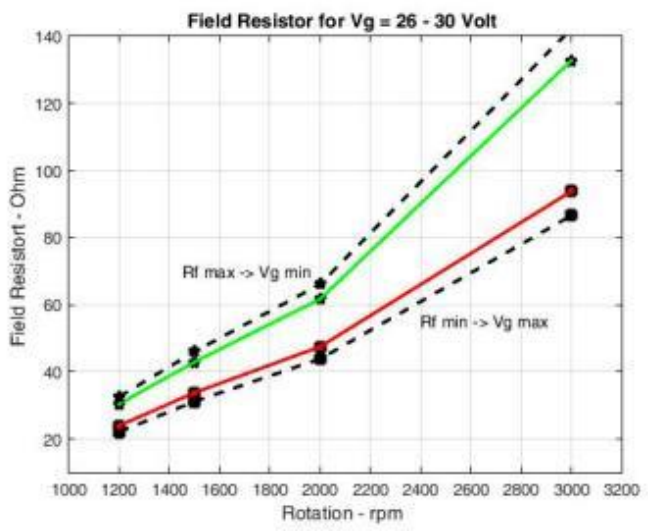

Fig. 5. Resistor field calculated

Fig. 5. shows the calculation results of the size of the resistor needed to adjust the field current, for a certain rotation. The dotted lines indicate the maximum and minimum ranges of the field resistors.

Based on the needs of the field resistor, a resistor level can be made that will be used to control the excitation current level. Then a multistage resistor will be arranged according to the required current at a constant voltage of 24 Volts, with the results as shown in Fig. 6.

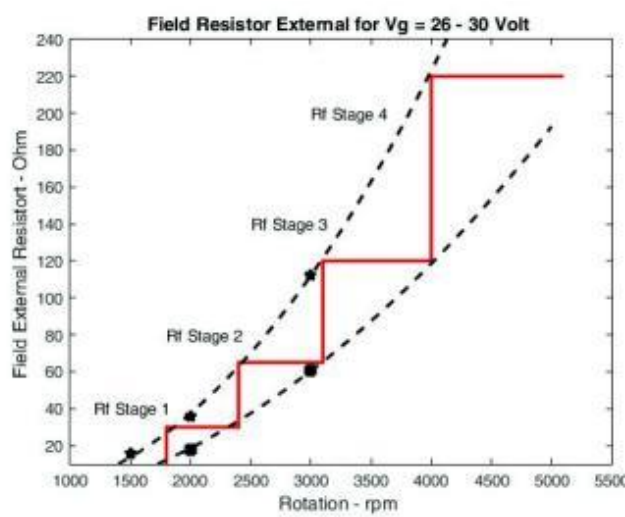

Fig. 6. Multistage field resistor

Fig. 6. shows the development of a multistage external resistor that will be used for excitation current control, which consists of 4 stages. This external resistor is an additional field wire resistance in addition to the field wire resistance itself. The resistance of the field coil wire itself and the resistance of the conducting stator coil wire is $28 \mathrm{Ohm}$. Then we get a multistage resistor of: stage $1 \mathrm{Rf}=30$, stage $2 \mathrm{Rf}=$ 65 , stage $3 \mathrm{Rf}=120$, stage $4 \mathrm{Rf}=220 \mathrm{Ohm}$.

\section{RESUlt AND DISCUSSION}

The results of the development of the AVR with a multistage comparator were carried out based on the multistage resistor in Fig. 6. and the size of the generator rotation which is reflected by the amount of the generator voltage that comes out. Then a 4 level voltage comparator is used, which will work sequentially. When the generator voltage has reached its maximum, the stage 1 resistor will first be activated and when the voltage crosses the limit again then the stage 2 resistor will be active and so on. Also if the voltage drops beyond the lower limit, the resistor will be deactivated sequentially. The results of the development of a DC generator AVR with various rotations are given in Fig. 7.

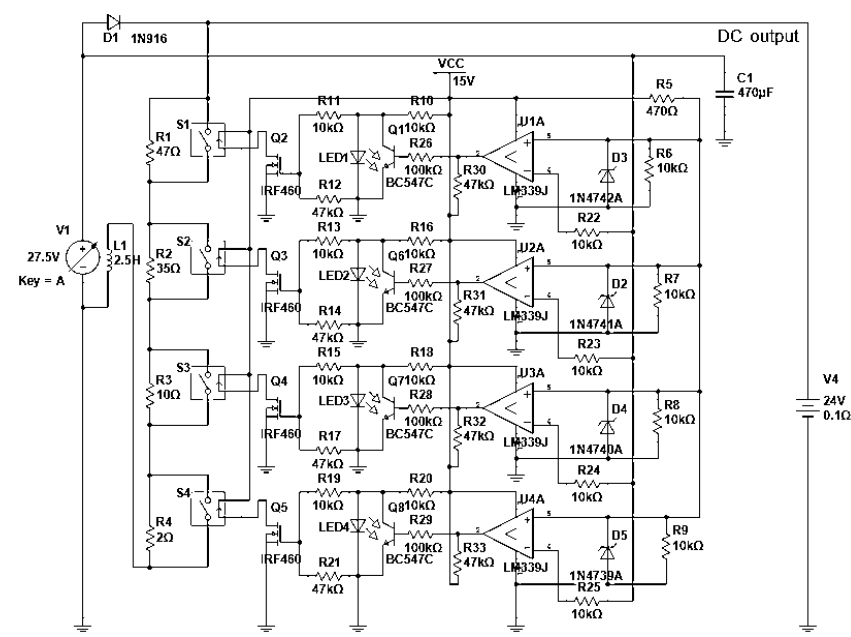

Fig. 7. AVR of variable speed DC generator

Fig. 7. shows a circuit diagram of the resulting AVR development of a variable speed DC generator, which will output a voltage between 26 - 30 Volts.

The final result of the performance of a DC generator with variable rotation with AVR with a multistage comparator is given in Fig. 8. In real experiments, the output current of the generator also depends on the battery 
condition. When the battery is empty, the generator will provide a higher current, conversely when the battery is full, the generator output current will decrease.

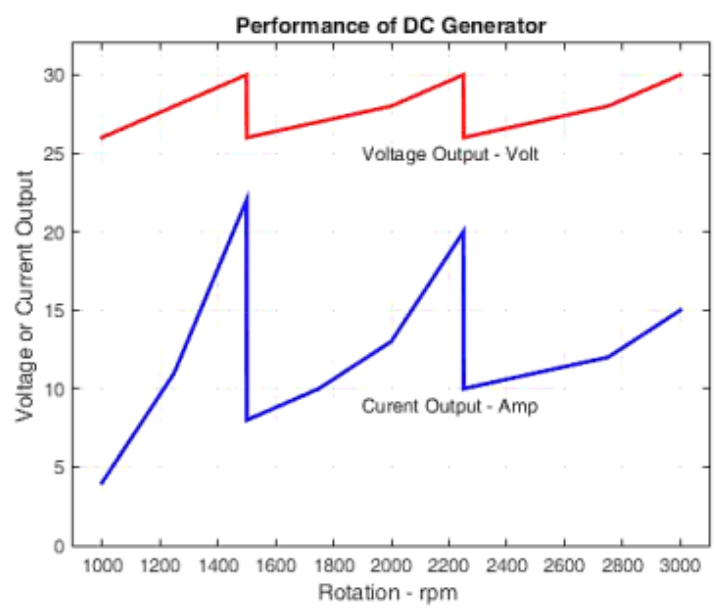

Fig. 8. Perforemance of DC generatorFig. 8. shows the performance of a generator equipped with a multistage comparator, which is operated at steady state. The current and voltage appear to go up and down according to the comparator stage displacement. Thus, the generator output current is able to meet the needs of the vehicle when it is operational and charging to the battery is quite controlled.

\section{CONCLUSION}

By using a multistage comparator, it can adjust the current and voltage of the rotating DC generator which is not fixed and varies widely. The output voltage ranges from 26 to 30 Volts and the output current ranges from 3 to 20 Amperes. This provides operational safety for the generator and battery. This system is based on an analog circuit which is quite responsive, but in the future it can be done with a digital system. This technology can be used in dc generator systems in automotive engines, windmills, and other power plants.

\section{REFERENCES}

[1] A. E. Fitzgerald, Charles Kingsley, Jr., Stephen D. Umans, Electric Machinery, McGraw-Hill, Boston, 2003.
[2] Prof. P. G. Dhawale, Prithviraj Patil, Nilesh Kumbhar, Rasika Mandlik, Pranali Nikam, Saraswati Kamble, Automatic Voltage Regulator, International Journal of Scientific Engineering and Science Volume 3, Issue 4, pp. 37-41, 2019.ISSN (Online):2456-7361, http://ijses.com/, 2019

[3] Matthew E. Oboh, Jafaru Braimah, Single Phase Automatic Voltage Regulator Design for Synchronous Generator, International Journal of Scientific \& Engineering Research, Volume 5, Issue 12, December2014, ISSN 2229-5518, 978-1-7281-3445-1/19/\$31.00 (C2019IEEE Xplore, 2019

[4] Siraparapu.Satyanarayana, Prof. R.K.Sharma, Asst.Prof. Mukta, Sappa.Anil Kumar, Automatic Generation Control in Power Plant using PID, PSS and Fuzzy-PID controller, 978-1-4799-41032/14/\$31.00@2014, IEEE Xplore, 2014

[5] D. S. Mota and C. Goldemberg, Comparison Between Voltage Control Structures of Synchronous Machines, IEEE LATIN AMERICA TRANSACTIONS, VOL. 8, NO. 6, DECEMBER 2010

[6] Fariya Tabassum, M. S. Rana, Robust Control of Terminal Voltage of an Isolated Electric Power Generating Unit, 1st International Conference on Advances in Science, Engineering and Robotics Technology2019(ICASERT 2019), 978-1-7281-3445-1/19/\$31.00 C) 2019IEEE Xplore, 2019

[7] M. Alberdi, M. Amundarain, AJ. Garrido, I. Garrido, F.J. Sainz, Control for Voltage Dips Ride-Through of Oscillating Water Columnbased Wave Power Generation Plant equipped with Doubly-Fed Induction Generator, 19th Mediterranean Conference on Control and AutomationAquis Corfu Holiday Palace, Corfu, GreeceJune 20-23, 978-1-4577-0123-8/11/\$26.00 @2011 IEEE Xplore, 2011

[8] Phuong T.H. Nguyen, S. Studli, J. H. Braslavsky, R. H. Middleton, Coordinated Control for Low Voltage Ride Through in PMSG Wind Turbines, IFAC PapersOnLine 51-28 (2018) 672-677, Science Direct, Elsevier, 2018

[9] Wojciech Wojtkowski, Digital control of a bidirectional DC/DC converter for automotive applications, IFAC Papers On Line 51-6 (2018) 113-118, Science Direct, Elsevier, 2018

[10] Sabin, Constantin Carpiuc, Corneliu Lazar, Multi-Rate Predictive Cascade DC-Link Voltage Control in Hybrid Electric Vehicles, 19th International Conference on System Theory, Control and Computing (ICSTCC), October 14-16, Cheile Gradistei, Romania, 978-1-47998481-7/15/\$31.00 @2015, IEEE Xplore, 2015

[11] Emre Çelika, Rafet Durgut, Performance enhancement of automatic voltage regulator by modified cost function and symbiotic organisms search algorithm, Engineering Science and Technology, an

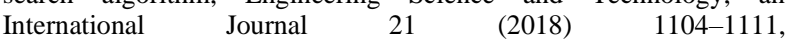
https://doi.org/10.1016/j.jestch.2018.08.006, Science Direct, www.elsevier.com/locate/jestch, 2018

[12] Du Bo, Liu Wenying, Wang Jiaming, Cui Gang, Zhang Bolin, The coordinating control measures of reactive power and voltage in the area with large-scale wind farms, 978-1-4577-0536-6/11/\$26.00 (C)2011 IEEE Xplore, 2011 